\title{
EVALUACIÓN POR CONTAMINACIÓN EN SUELOS ALEDAÑOS A LOS CEMENTERIOS JARDINES DEL RECUERDO E INMACULADA
}

\author{
ASSESSMENT BY SOIL POLLUTION BORDERING BURIAL GROUNDS JARDINES DEL RECUERDO \\ AND INMACULADA \\ Aurora Velasco Rivera \\ Ingeniero Civil M.Sc. Facultad de Ingeniería, Investigadora grupo VCH \\ Universidad Militar Nueva Granada, Bogotá, Colombia \\ aurora.velasco@unimilitar.edu.co \\ Yudy Marlevis Minota Zea \\ Estudiante egresada Ingeniería Civil \\ Universidad Militar Nueva Granada, Bogotá, Colombia \\ yudyminotazea@gmail.com
}

Fecha de recepción: 2 de diciembre de 2011

Fecha de aprobación: 30 de mayo de 2012

\section{RESUMEN}

Los cementerios son sitios para la disposición final de los cuerpos humanos que constituyen un foco de contaminación por los lixiviados que genera la descomposición cadavérica. Este material contiene sustancias peligrosas, como putrescina y cadaverina, microorganismos patógenos, metales pesados, isótopos radiactivos y dioxinas que pueden pasar a través del suelo y llegar a las aguas subterráneas. Como existe muy poca información sobre el tema, el trabajo consistió en tomar muestras del suelo en los cementerios Jardines del Recuerdo e Inmaculada (Bogotá) y en zonas aledañas, para determinar su pH, salinidad y contenido en amonio y nitratos, con el fin de analizar preliminarmente la incidencia de los lixiviados en la contaminación del suelo.

Palabras clave: cementerios, contaminación, lixiviados, cadaverina, putrescina, amoniaco, nitratos.

\begin{abstract}
Burial grounds are disposal sites for human bodies and a source of pollution due to leachate generated by decomposition of corpses. That material contains hazardous substances, such as putrescine and cadaverine, pathogens, heavy metals, radioactive isotopes and dioxins, which can pass through the soil and reach groundwater. Since there is very little information on this
\end{abstract}


subject, our task was taking soil samples at cemeteries Jardines del Recuerdo and Inmaculada and surrounding areas in Bogota to determine its $\mathrm{pH}$, salinity and ammonium and nitrates contents in order to analyze previously the impact of leachate on pollution of soil.

Keywords: burial grounds, pollution, leachate, putrescine, cadaverine, ammonia, nitrates.

\section{INTRODUCCIÓN}

El suelo es la capa no consolidada y superior de la corteza terrestre, biológicamente activa, que se forma a partir de las rocas y por influencia de la intemperie y de los seres vivos y además, posee propiedades que contribuyen con el proceso de generación de vida y la producción de alimentos, fibras, maderas y otras materias primas. El suelo no sólo soporta la vida de muchos animales y microorganismos, sino que también sirve como sumidero de diversas sustancias que el hombre acumula en él, entre ellas, los lixiviados que generan las basuras o la sepultura de cadáveres.

La actividad de los parques cementerio puede ocasionar problemas de salud pública por epidemias y bacterias que se alojan en el suelo debido a la contaminación por lixiviados que libera el proceso de descomposición de los cadáveres, sustancias que pueden infiltrarse a través del suelo y llegar a los depósitos de agua subterránea en las zonas aledañas [1, 8].

Uno de los sitios más afectados con esta problemática es la ciudad de Lima (Perú), donde llueve muy poco durante el año [2], por lo cual no hay suficientes corrientes de agua que arrastren los lixiviados y los contaminantes se mantienen en el suelo, propiciando la contaminación de los pocos depósitos de agua subterránea que surten de agua potable a la población. Por tal razón, la mayoría de estudios sobre este tema se han hecho en Lima. Los estudios sobre contaminación por lixiviados de cadaverina en suelos son muy pocos, porque es más común realizar este tipo de pruebas en aguas subterráneas.

En Colombia, las investigaciones se han encaminado hacia la parte hidrológica, debido a que el agua es abundante en nuestro País, dejando de lado la investigación química de los suelos que constituyen un depósito de contaminantes de gran importancia. Los estudios se harán en zonas aledañas a los cementerios Jardines del Recuerdo e Inmaculada, sitos en donde se tomarán muestras para llevar a cabo estudios químicos de pH, conductividad eléctrica, nitrógeno total, nitratos, acidez, humedad actual y humedad equivalente, que permitirán elaborar el diagnóstico final.

La contaminación del suelo se produce por la introducción en él, de sustancias químicas u otro material que se encuentra fuera de lugar y presente en concentraciones mayores a las naturales, lo cual implica pérdida de capacidad para su uso y amenazas para la salud. 
Un terreno se puede degradar al acumular desechos a tales niveles que repercutan negativamente en su comportamiento, de manera que a esos niveles de concentración, se vuelven tóxicos para los organismos del suelo. Se trata pues de una degradación química que provoca la pérdida parcial o total de la productividad del suelo $[10,11]$.

Los ataúdes generan contaminación mediante la volatilización de sustancias tóxicas como barnices y disolventes, y por elementos (zinc y plomo), que se esparcen por el suelo. Los materiales internos de los ataúdes también contribuyen a generar impacto ambiental [1, 3].

La generación de riesgo disminuiría, si los cementerios tuvieran un sistema interno de drenaje, para capturar los lixiviados y proceder a su tratamiento, lo mismo que las fosas tuvieran un revestimiento interior en concreto, que permitiera el uso de sustancias químicas o biológicas para acelerar la degradación de los cuerpos.

El plan de ordenamiento zonal cerca de los Cementerios Jardines del Recuerdo e Inmaculada, presenta dos bio-ambientes: el primero está compuesto por la Sabana con la zona plana del hospital Simón Bolívar y los cementerios; y el segundo por los humedales y quebradas con la sub.cuenca de Torca [4]. Los humedales La Conejera, Torca y Guaymaral ejercen sobre la zona, un proceso de regulación del agua, por que recogen las aguas lluvias y las descargan al río Bogotá en época de invierno, y regulan el nivel freático durante la época de verano. Su principal función es ser el hábitat de diferentes especies de fauna y flora, y permitir la mejora de la calidad del agua [7].

Algunas edificaciones del área de influencia de los cementerios del norte, tales como universidades y colegios, y los mismos cementerios, se abastecen de agua por medio de pozos profundos y drenan sus aguas residuales a través de pozos sépticos o de vallados (cauces naturales de agua estancada), originalmente usados para drenar las aguas lluvias [4]. Dada la cercanía con los cementerios, conviene llevar a cabo un análisis en laboratorio para identificar la contaminación que se está generando en el suelo y en el agua subterránea, consecuencia de los lixiviados producidos por los cadáveres enterrados en la zona.

Este trabajo constituye apenas, la parte inicial de la investigación de contaminación generada por los parques cementerio, y su objetivo es identificar sustancias que indiquen contaminación por diaminas (putrescina y cadaverina), entre las cuales se encuentran el amonio y los nitratos.

\section{MATERIALES Y MÉTODOS}

Se hicieron cuatro visitas a los lugares marcados en el mapa de la zona Norte de Bogotá (Figura 1), en donde se tomaron 16 muestras del suelo. Las muestras se identificaron por campaña y lugar de donde fueron extraídas para tener un orden cronológico de las mismas, y llevar un análisis que involucrara algunos factores como el clima y la temperatura. 


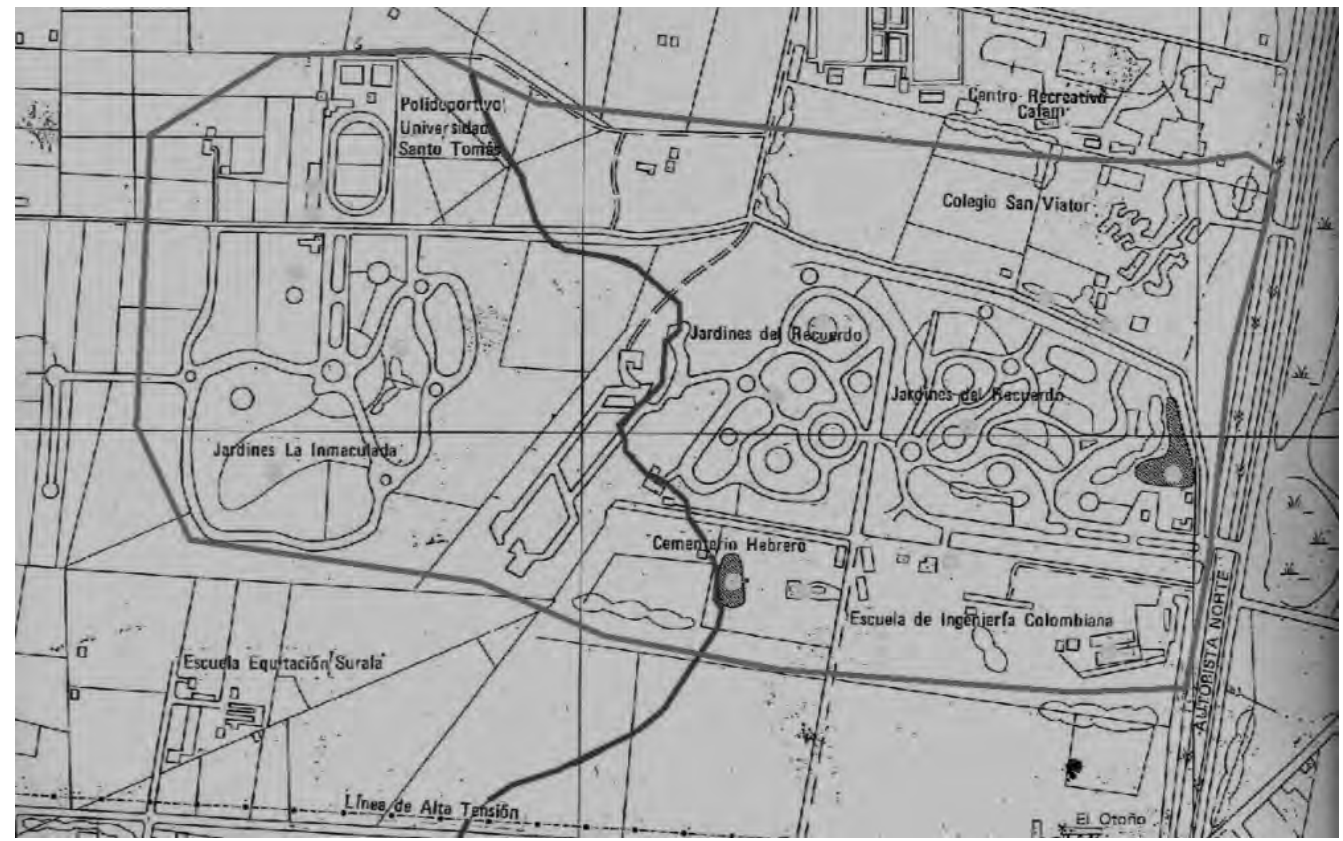

Figura 1. Identificación de los puntos de muestreo

Fuente: Instituto Geográfico Agustín Codazzi (IGAC)

Las muestras tomadas en los cementerios Jardines del Recuerdo e Inmaculada fueron recolectadas en lugares donde ya se había hecho una excavación previa para llevar a cabo el entierro de cuerpos. Estás excavaciones fueron hechas a una profundidad entre 1 metro con $80 \mathrm{~cm}$ y $2 \mathrm{~m}$. Para las demás muestras, se tuvo que hacer apiques en lugares estratégicos para observar si había algún grado de contaminación. El transporte de las mismas se hizo en bolsas Ziploc que permiten un empaque al vacío para que el suelo no pierda sus propiedades químicas. Las muestras tomadas en campo, se llevaron al laboratorio para los siguientes análisis: humedad natural, pH, acidez intercambiable, conductividad eléctrica, materia orgánica, nitrógeno total.

La acidez intercambiable (A.I), fue hallada con $\mathrm{KCl} 1 \mathrm{~N}$ y determinada con la ayuda de un titulante $\mathrm{NaOH} 0.01 \mathrm{~N}$; para el $\mathrm{pH}$ se hizo una extracción en $\mathrm{H}_{2} \mathrm{O}$ y una determinación por potenciómetro; el nitrógeno $(N)$ total, fue determinado por semi-microKjeldahl y ensayo de nitratos con el fin de asociar la presencia de cadaverina y putrescina en las muestras de suelo, extraídas con $\mathrm{KCl} 2 \mathrm{~N}$, al igual que el amonio. El carbón orgánico (C.O), fue determinado por el método de Walkley - Black y la Conductividad eléctrica (CE), en extracto de saturación. Estos procesos se llevaron a cabo, siguiendo los parámetros químicos necesarios.

El porcentaje de humedad natural se determinó, introduciendo las muestras en las cápsulas metálicas pesadas con anterioridad y luego secada a $105^{\circ} \mathrm{C}$ por un tiempo no mayor a 24 horas, teniendo en cuenta el proceso de enfriado y luego la toma de un peso de las muestras [5, 9]. 


\section{RESULTADOS Y DISCUSIÓN}

Los resultados que se presentan a continuación, reflejan que el suelo de la zona Norte de la ciudad de Bogotá es muy ácido por ser un área acuosa y con un grado elevado de aporte vegetal; la actividad bacteriana presente en el lugar es alta y permite que el pH sea menor a 6 . Todos los resultados se presentan en porcentaje, con excepción del pH, la acidez intercambiable y la salinidad. Las Tablas 1 y 2 presentan los resultados de los ensayos efectuados en el sitio.

Tabla 1. Resultados de los ensayos por sitio de muestreo.

\begin{tabular}{|c|c|c|c|c|c|}
\hline PUNTO DE MUESTREO & $\mathbf{P h}$ & $\mathbf{N}$. Total (\%) & $\begin{array}{c}\text { SALINIDAD } \\
\text { ce (ds/m) }\end{array}$ & $\mathbf{N}^{-\mathbf{N H}_{\mathbf{4}}} \mathbf{~ ( \% )}$ & $\mathbf{N}^{\mathbf{N} \mathbf{O}_{\mathbf{3}} \text { (\%) }}$ \\
\hline 1. Jardines Recuerdo & 5,370 & 0,7700 & 0,30 & 0,0005050 & 0,002300 \\
\hline 2. Escuela de Ingen. & 5,725 & 0,6100 & 0,50 & 0,0001380 & 0,000428 \\
\hline 3. Colegio San Viator & 5,800 & 0,4025 & 0,22 & 0,0005650 & 0,001578 \\
\hline 4. Inmaculada & 5,300 & 0,8275 & 0,33 & 0,0005025 & 0,002100 \\
\hline
\end{tabular}

Tabla 2. Resultados promedio obtenidos en sitio de cada punto de muestreo

\begin{tabular}{|c|c|c|c|c|c|c|c|c|c|}
\hline FECHA & $\begin{array}{l}\text { PUNTO DE } \\
\text { MUESTREO }\end{array}$ & $\mathrm{Ph}$ & C.O.\% & $\begin{array}{l}\text { N. Total } \\
\%\end{array}$ & $\begin{array}{c}\text { Ai ACIDEZ } \\
\text { INTERCAMB. } \\
\text { Cmol|+l//kg }\end{array}$ & $\begin{array}{l}\text { SALINIDAD } \\
\text { ce (ds/m) }\end{array}$ & $\begin{array}{l}\mathrm{N}-\mathrm{NH}_{4} \\
|\%|\end{array}$ & $\begin{array}{c}\mathrm{N}-\mathrm{NO}_{3} \\
|\%|\end{array}$ & $\begin{array}{c}\text { HUMEDAD } \\
\text { NATURAL } \\
\%\end{array}$ \\
\hline \multirow{4}{*}{ 08-abr-10 } & 1. Jardines Recuerdo & 5,3 & 7,2 & 0,77 & \multirow{4}{*}{0,34} & 0,28 & 0,00051 & 0,0023 & 56,3 \\
\hline & 2. Escuela de Ingen. & 5,8 & 6,7 & 0,60 & & 0,48 & 0,00013 & 0,00042 & 59,2 \\
\hline & 3. Colegio San Viator & 5,7 & 4,1 & 0,40 & & 0,21 & 0,00055 & 0,00157 & 43,8 \\
\hline & 4. Inmaculada & 5,4 & 7,4 & 0,82 & & 0,31 & 0,00048 & 0,00210 & 57,4 \\
\hline \multirow{4}{*}{ 15-abr-10 } & 1. Jardines Recuerdo & 5,4 & 7,5 & 0,76 & \multirow{4}{*}{0,34} & 0,28 & 0,00052 & 0,00250 & 55,1 \\
\hline & 2. Escuela de Ingen. & 5,7 & 6,9 & 0,59 & & 0,46 & 0,00014 & 0,00043 & 60,1 \\
\hline & 3. Colegio San Viator & 5,6 & 3,8 & 0,40 & & 0,22 & 0,00057 & 0,00160 & 44,5 \\
\hline & 4. Inmaculada & 5,1 & 7,6 & 0,8 & & 0,32 & 0,00049 & 0,00220 & 57,1 \\
\hline \multirow{4}{*}{ 22-abr-10 } & 1. Jardines Recuerdo & 5,5 & 7,3 & 0,78 & \multirow{4}{*}{0,34} & 0,30 & 0,00049 & 0,00200 & 53,8 \\
\hline & 2. Escuela de Ingen. & 5,8 & 6,6 & 0,61 & & 0,50 & 0,00013 & 0,00045 & 59,7 \\
\hline & 3. Colegio San Viator & 6,0 & 4,3 & 0,42 & & 0,21 & 0,00056 & 0,00155 & 43,2 \\
\hline & 4. Inmaculada & 5,3 & 7,2 & 0,84 & & 0,33 & 0,00051 & 0,00200 & 58,6 \\
\hline \multirow{4}{*}{ 29-abr-10 } & 1. Jardines Recuerdo & 5,3 & 7,2 & 0,77 & \multirow{4}{*}{0,34} & 0,32 & 0,00050 & 0,00240 & 57,2 \\
\hline & 2. Escuela de Ingen. & 5,6 & 6,8 & 0,62 & & 0,52 & 0,00015 & 0,00041 & 58,6 \\
\hline & 3. Colegio San Viator & 5,9 & 4,2 & 0,39 & & 0,23 & 0,00058 & 0.00159 & 43,6 \\
\hline & 4. Inmaculada & 5,4 & 7,3 & 0,85 & & 0,35 & 0,00053 & 0,00210 & 59,2 \\
\hline
\end{tabular}


Las precipitaciones en el lugar son drenadas por el suelo y en épocas lluviosas, se mantiene una ligera capa de agua que hace que se conserve la humedad en la zona [3]. La capa vegetal aporta acidez al suelo que aumenta por la descomposición de grandes cantidades de materia orgánica. La humedad natural contribuye a la descomposición de la materia orgánica, permitiendo que los microorganismos lleven a cabo su función, e influyen en la disponibilidad de oxígeno en el suelo ya que el $\mathrm{O}_{2}$ presenta un bajo grado de solubilidad en el agua. Los resultados en porcentaje obtenidos de la humedad natural oscilan entre 55,6-58,07\%, los cuales no presentan inconveniente por el tipo de zona en donde no hay edificaciones de gran envergadura que estén en riesgo por saturación del suelo.

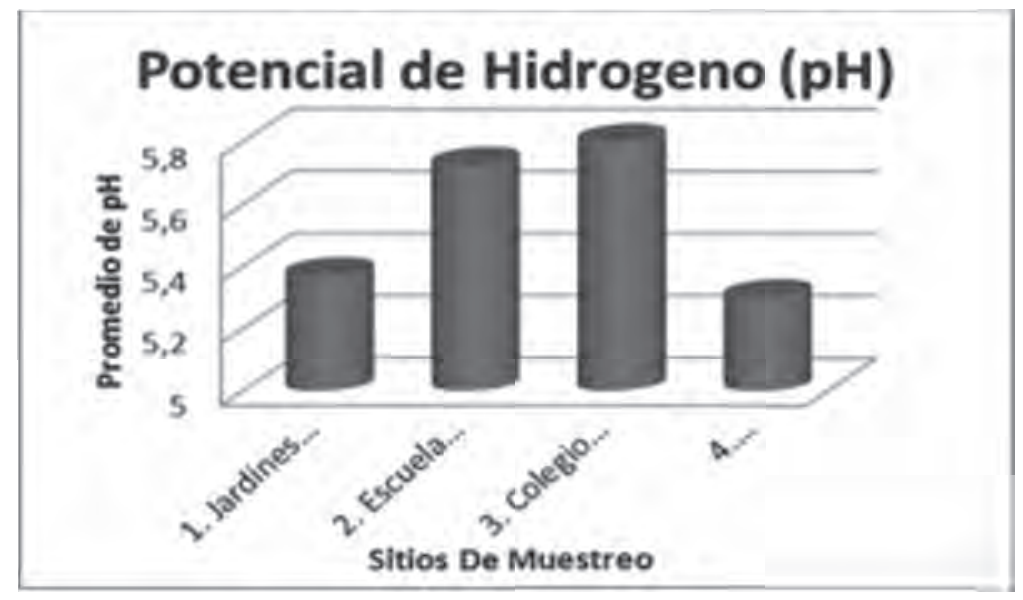

Figura 2. Valor mínimo aceptable del pH = 5.54

La acidez de un suelo depende de la concentración de hidrogeniones $[\mathrm{H}+]$ en la solución de las aguas y se caracteriza por el valor del pH, que señala cuándo un suelo es ácido o alcalino [5]. En los análisis efectuados, se encontró que todas las muestras presentan un pH ácido entre 5.1 y 6.0, y un valor promedio de 5.55 (Figura 2).

La contaminación notoria se halla en los cementerios Jardines del Recuerdo y La Inmaculada, lo cual permite entender que las zonas aledañas a los cementerios están de cierta manera menos afectadas, aunque se debe tener en cuenta que estas área tienen contacto directo con los humedales que generan un grado de contaminación, dependiendo de la proximidad con ellos.

Al relacionar el grupo amonio que tiene carácter básico, con el $\mathrm{pH}$, se observa que el pH es mayor en el colegio San Viator y coincide con la mayor cantidad de amonio. Es normal que en suelos de clima frío, se hallen concentraciones más altas de nitrógeno total que en otros climas. Factores como el pH, la temperatura, la aireación y el contenido de agua propician el ambiente adecuado porque disminuyen la actividad microbiana, causando la acumulación de materia orgánica en áreas que se inundan. 
Suelos con un porcentaje superior a $0.221 \%$, se consideran extremadamente ricos en nitrógeno total [6]. Los rangos encontrados en el área de estudio, estuvieron entre 0,77 y 0,82 \% (Figura 3).

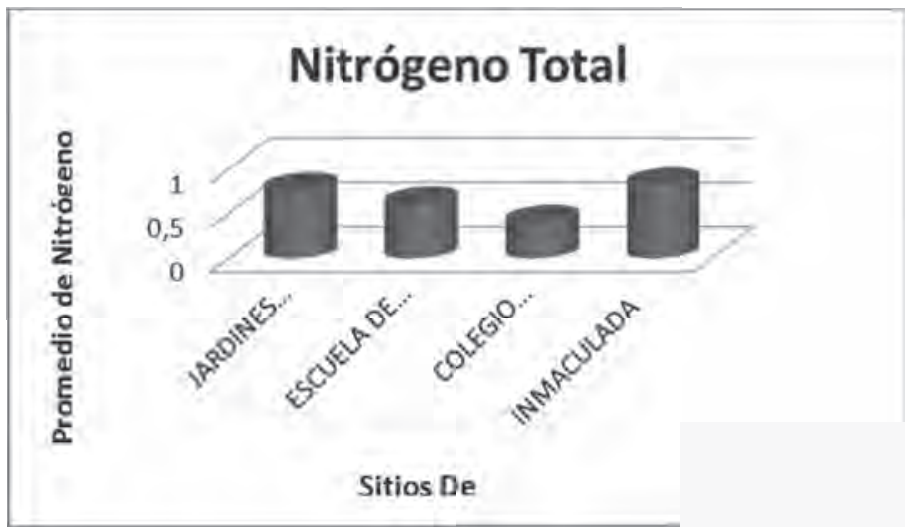

Figura 3. Valores promedios de zonas de estudio.

La presencia de nitrógeno en estos suelos, es muy alta debido al gran contenido de materia orgánica, y a la influencia de la humedad y las bajas temperaturas que han favorecido la actividad microbiana para la constante liberación del elemento en estudio.

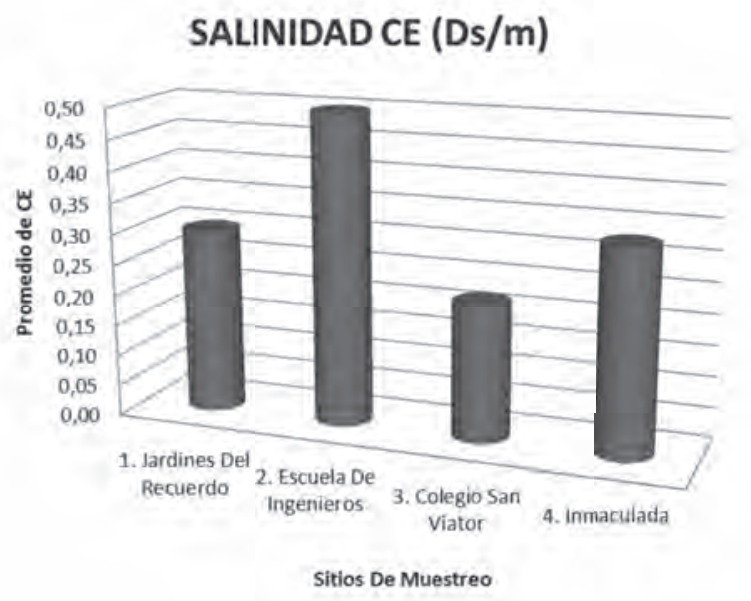

Figura 4. Valores promedios de Salinidad en zonas de estudio.

Los datos obtenidos en los ensayos de conductividad eléctrica en las muestras llevadas a laboratorio, muestran un rango de 0,22 a 0,50 (dS/m) que indica que es un suelo normal, pues su porcentaje es inferior a 15\%, lo cual no implica algún riesgo de que el agua filtrada en estos suelos, presente altos contenidos de salinidad y si fuere usada en riego de cultivos no afectaría 
la salud humana (Figura 4). En climas húmedos, donde llueve mucho, es raro que haya suelos salinos, puesto que las sales son drenadas en profundidad y no afectan la zona de las raíces de los cultivos y/o plantas.

Con respecto del amonio, el sitio con mayor cantidad es el colegio San Viator con 0,00057\% seguido por los Jardines del Recuerdo con 0,000505\% y la Inmaculada con 0,0005025\%. El valor más bajo corresponde a la Escuela de Ingenieros con 0,000138\% (Figura 5).

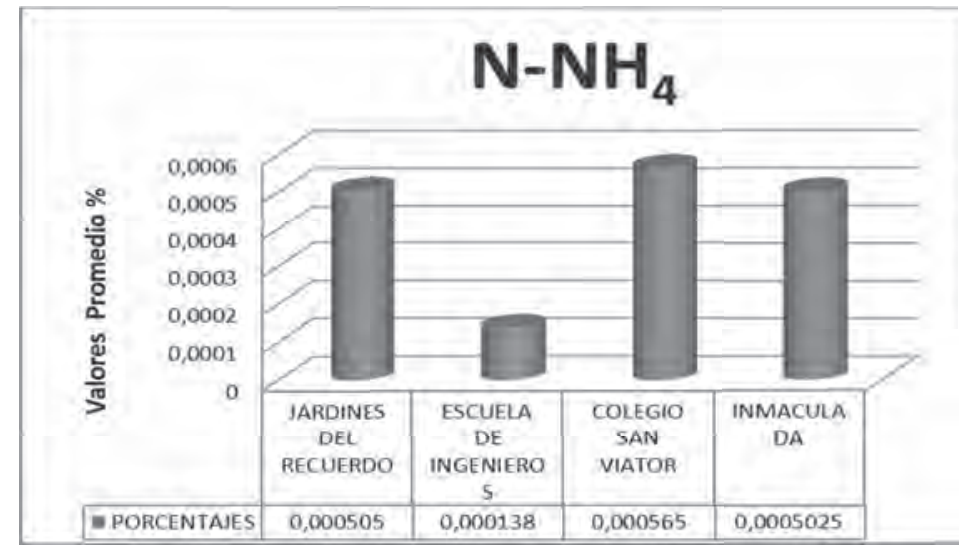

Figura 5. Valores promedios de amonio en zonas de estudio

Se encontraron cantidades representativas de nitratos en Jardines del Recuerdo, Inmaculada y colegio San Viator (Figura 6), siendo Jardines del Recuerdo el sitio con mayor cantidad de nitratos 0,0023\% seguido por la Inmaculada con 0,0021\% y el colegio San Viator con 0,0016\%; el valor más bajo fue en la Escuela de Ingeniería con 0,00043\%.

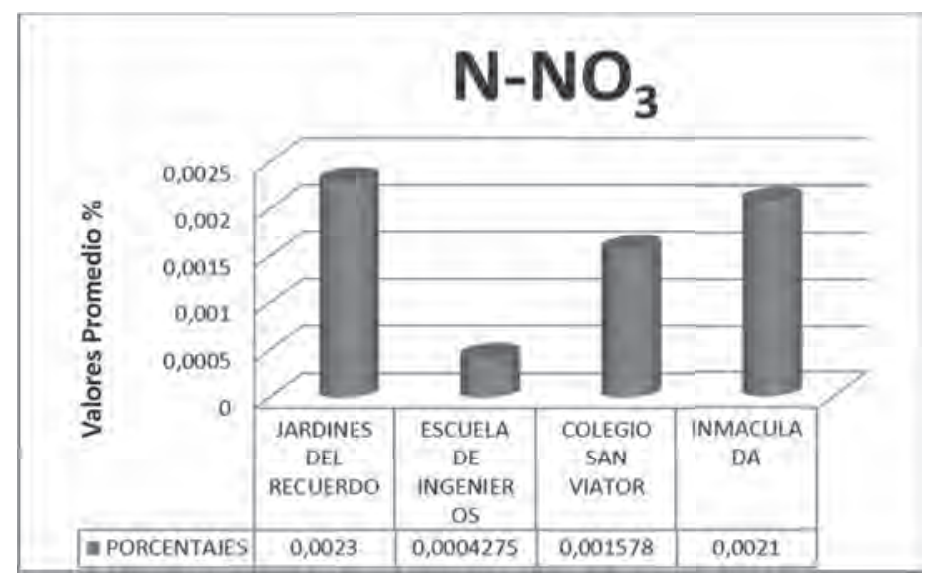

Figura 6. Valores promedios de Nitratos en zonas de estudio 
De acuerdo con lo anterior, el sitio menos afectado es la Escuela de Ingeniería, pues se observa gran contaminación en los dos cementerios y en el colegio San Viator, dada su cercanía con el humedal de Torca - Guaymaral que en la actualidad, presenta problemas de contaminación por la siembra de pastos para ganadería y la proliferación de urbanizaciones. El sistema de humedales de Torca recoge aguas lluvias y algunas conexiones erradas en la parte oriental y sur oriental de la zona Norte de la ciudad y los descarga en el canal de Torca, lo cual hace que se generen focos y amenazas de inoculación en el suelo y por consiguiente, infiltración de los mismos en las aguas subterráneas.

Por otra parte, la cantidad de nitratos hallada en la Escuela de Ingeniería es poco representativa en comparación con los otros puntos de muestreo por la distancia que hay entre la Escuela y el humedal de Torca, y por la poca exposición a zonas agrícolas.

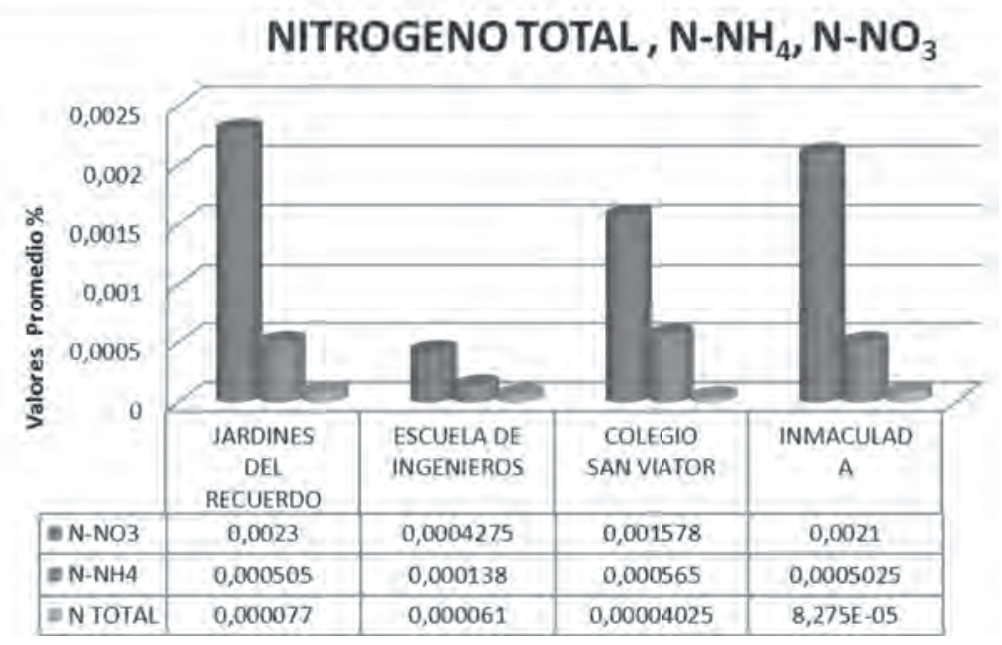

Figura 7. Valores promedio de Nitrógeno Total, $\mathrm{N}-\mathrm{NH}_{4} \mathrm{Y} \mathrm{N}-\mathrm{NO}_{3}$

Un análisis general de la Figura 7, permite determinar que la principal contaminación del suelo se debe a nitratos, presentes en mayor cantidad en los cementerios, lo cual es lógico debido a que los nitratos son el producto final de la oxidación de la materia orgánica nitrogenada en putrefacción (cadáveres). Un suelo rico en nitratos produce plantas exhuberantes pero cuando no es aprovechado por ellas, este elemento puede llegar al agua subterránea y la vuelve potencialmente peligrosa para la salud humana, dado que en contacto con plomo y otros metales hace que aquellas se disuelvan. 


\section{CONCLUSIONES}

Cementerios como Jardines del Recuerdo, presentan actividades tales como: alquiler de lotes en predios que se encuentran en inmediaciones del humedal de Torca, lo cual hace que haya impacto negativo en las condiciones naturales de la zona y afecten su fauna y flora, por lo cual la Alcaldía Mayor de Bogotá ha impuesto varias multas a estas entidades [7]. Por lo anterior, se recomienda que se apliquen a fondo los métodos de mitigación y prevención para enfretar la invasión progresiva de agentes externos en esta zona.

Al relacionar el grupo amonio, que tiene carácter básico, se observa que el pH es mayor en el colegio San Viator, coincidiendo con la mayor cantidad de amonio que podría deberse al uso de plaguicidas, por que tradicionalmente estos terrenos han sido zonas cultivables.

Es normal que en suelos de clima frío, se hallen concentraciones más altas de nitrógeno total que en otros climas. Factores como el pH, la temperatura, el aire y el contenido de agua propician el ambiente adecuado al disminuir la actividad microbiana, y acumula materia orgánica en áreas que se inundan.

Los nitratos permiten ver la contaminación de mayor período y, en este caso, se da en los cementerios por la descomposición rápida de los cadáveres, y por la cercanía con el humedal de Torca.

La contaminación más notoria se halla en el cementerio Jardines del Recuerdo y La Inmaculada, lo cual permite entender que las zonas aledañas a los cementerios están de cierta manera menos afectadas, pero se debe tener en cuenta que esta área tiene contacto directo con los humedales que generan un grado de contaminación según la proximidad con ellos.

Los cementerios Jardines del Recuerdo e Inmaculada tienen mayor cantidad de nitratos debido a la descomposición de aminoácidos provenientes de los cadáveres.

La función de filtrado que cumple el suelo, permite que la cantidad de nitratos del agua subterránea sea menor, debido a la retención que ejercen los poros más pequeños.

La generación de riesgo disminuiría, si los cementerios tuvieran un sistema interno de drenaje con el fin de capturar los líquidos lixiviados para su posterior tratamiento, y si las fosas fueran construidas con un revestimiento interior en concreto que permitiera usar sustancias químicas o biológicas para acelerar la degradación de los cuerpos.

Para futuras investigaciones, conviene ampliar el analisis en zonas aledañas a cementerios y en otras zonas de Bogotá, durante la época de lluvias y de verano, y a diferentes profundidades. Para ello, se puede acudir a métodos hidrogeológicos y geofísicos, con el fin de detectar las filtraciones de agua, y demostrar la trayectoria de los contaminantes. También se deberá contemplar algunas soluciones a los problemas de contaminación. 


\section{REFERENCIA BIBLIOGRAFICA}

[1] Espinoza Eche José Jorge. Evaluación de impacto ambiental de un cementerio tipo parque ecológico. En: http://mww.scielo.org.pe/pdf/iigeo/v4n8/a07v4n8.pdf (abril de 2011).

[2] UNFV EUPG. Evaluación y Gestión de Riesgos por Cementerios en Lima Metropolitana y Callao. En: http://mww.bvsde.paho.org/bvsacd/cd61/aranibar/anexo.pdf (enero de 2011).

[3] Beltrán M., y Miralles J., (2005). Ecofunerales. Revista virtual Perspectiva ambiental 35. Fundación Terra, Barcelona. En: http://es.scribd.com/doc/30411595/PERSPECTIVAAMBIENTAL-ECofunerales

(abril de 2010).

[4] Alcaldía Mayor de Bogotá, Secretaría Distrital de Planeación., (2009). En: http://www. alcaldiabogota.gov.co/ (marzo de 2010).

[5] Instituto Geográfico Agustín Codazzi., (2006). Métodos Analíticos del Laboratorio de Suelos, 6a. Ed. Imprenta Nacional de Colombia. Bogotá; 648 p.

[6] Moreno D.R., (1978). Clasificación de pH del suelo, contenido de sales y nutrientes asimilables. INIA-SARH, México.

[7] Acueducto y Alcantarillado de Bogotá. Humedales del distrito capital. En: www.acueducto. com.co/wpsv5/wps/html/html/ambiental/humedales/pop.htm (febrero de 2011 ).

[8] Alcaldía Mayor de Bogotá. Decreto 313 de 2006, Por el cual se adopta el Plan Maestro de Cementerios y Servicios Funerarios para el Distrito Capital -PMCSF- y se dictan otras disposiciones.

[9] APHA, AWWA, WPCF (1976). "Standard Methods for the Examination of Water and Wastewater". USA.

[10] MAE. Informe ambiental de la calidad de suelos. En: http://Mmw.ambiente.gov.ec/ userfiles/552/file/Junio202009\%20Segunda/Informe_MAE.pdf (septiembre de 2009).

[11] Sawyer C.N. et al, (2001). Química para Ingeniería Ambiental. McGraw Hill. Bogotá. 
